\title{
Nota historica: A primeira turma da Faculdade de Medicina de Ribeirão Preto - USP
}

brmandos da primeira turma da Facul-
dade de Medicina de Ribeirão Preto:
Akio Tanaka, Alberto Blucher, Armando Maestrello, Arthur José Suzanna, Astíage Beligne Filho, Aureliano Fernandes Schimidt, Carlos Roberto Caliento, Clara de Rosa Carelli, Clarimundo Alves de Souza Filho, Denizard Rivail Gomes, Duílio Gomes Pereira da Silva, Ernaldo de Freitas Menezes, Eusa Cremonesi, Geraldo Alves Correa Netto, Gilberto Rocha Menezes, Hemil Riscalla, Íris Ferrari, Ivone Milan, João José De Cunto, João Romera, Johann Eugen Kunzle, José Lancha Filho, José Martins Orso, Josmar Elias Bueno, Keiko Marufuji, Kiuro Hirata, Laone Gessy Sperandio, Luiz Bernardi, Maria Ivonete Dias de Abreu, Mario Buzzi Filho, Milton Catapano, Milton Peixoto, Nelson Augusto, Oswaldo Munhoz, Paulo Hiroshi Mitsui, Paulo Ogawa, Nelson Caprini, Octávio Ruas Álvares, Oswaldo Garcia Maldonado, Renato Andretto, Roberto Ernesto Lagana, Vinício Plastino e Virgilio de Carvalho Neves.

Infelizmente, cerca de 16 deles já nos deixaram. À eles nossa saudade e aos quais prestamos nossas homenagens. São os assinalados em negrito.

Os remanescentes desta $1^{\text {a }}$ turma da Faculdade estão completando 50 anos de conclusão do curso de medicina.

Em 1952, venceram o primeiro vestibular desta escola e conseguiram galgar sua matrícula no primeiro ano.

Em 1957, seis anos depois, concluíram o curso e receberam os seus Diplomas de Médico das mãos do Paraninfo da turma, Professor Zeferino Vaz, que era o Diretor da Escola e que foi o idealizador e fundador desta Faculdade.

Os remanescentes que ai estão desta $1^{\text {a }}$ turma têm muita história para contar, pois, participaram da instalação de uma faculdade, completamente diferente das outras, inovadora em todos os sentidos. O nú- mero de cátedras foi reduzido, de 35 em outras faculdades, passou a ter somente 20, nesta; o número de horas de algumas disciplinas foi reduzido, e este número foi aumentado em outras que eram mais necessárias para o curso médico; as técnicas de ensino introduzidas foram revolucionárias, o ensino puramente informativo cedeu lugar ao ensino em que o aluno tem que buscar as soluções dos inúmeros problemas da carreira médica; a carreira didática foi completamente reestruturada, dando méritos a quem merece; foi estabelecido o tempo integral e exclusivo para os professores; foi introduzida uma disciplina que não existia em outras faculdades, criando-se assim o Departamento de Psicologia Médica.

Estes alunos assistiram e participaram, desde o início da instalação paulatina dos diversos departamentos da Faculdade.

Criaram o Centro Acadêmico Rocha Lima, desde a redação do seu estatuto, bem como participaram da sua diretoria, sendo que três alunos desta turma ocuparam a presidência do Centro Acadêmico nos seus primeiros anos de vida da Faculdade.

Criaram a Associação Atlética, restauraram o Ginásio de Esportes que estava abandonado há muitos anos.

Assistiram e participaram da instalação do Hospital das Clínicas, na cidade, hoje Unidade de Emergência deste Hospital.

Enfim, pode-se dizer que todos viveram as transformações físicas, didáticas e culturais que se sucederam, em todas as áreas da Faculdade.

Encerrando, queremos relatar o relacionamento espetacular que existiu entre estes alunos desta turma e seus mestres: catedráticos, docentes, assistentes, e sobretudo, com todos os funcionários desta Faculdade, e principalmente com a direção da escola.

Dr. Carlos Roberto Caliento Aluno da Primeira Turma da FMRP-USP 